\title{
Effects of compound 21, a non-peptide angiotensin II type 2 receptor agonist, on general anesthesia-induced cerebral injury in neonatal rats
}

\author{
JUN YONG, LI YAN, JING WANG, HONGMEI XIAO and QINGFAN ZENG \\ Department of Anesthesiology, The Baiyun Hospital Affiliated to Guizhou Medical University, \\ Guiyang, Guizhou 550014, P.R. China
}

Received January 19, 2018; Accepted August 22, 2018

DOI: $10.3892 / \mathrm{mmr} .2018 .9602$

\begin{abstract}
General anesthesia has a great impact on neurodevelopment. However, the mechanisms underlying this effect and therapeutic methods to address it remain limited. The present study aimed to investigate the effects of compound (C)21, a non-peptide angiotensin II type 2 receptor agonist, on general anesthesia-induced cerebral injury in neonatal rats. Neonatal Sprague Dawley rats (postnatal day 7) were randomly divided into three groups ( $n=6$ per group): The control, isoflurane and $\mathrm{C} 21+$ isoflurane (C21) group. General anesthesia was induced through inhalation of $1.3 \%$ isoflurane. Apoptosis and synaptic structure were analyzed. The levels of peroxisome proliferator-activated receptor (PPAR)- $\alpha$ were detected using an enzyme-linked immunosorbent assay. BCL2, apoptosis regulator ( $\mathrm{Bcl}-2)$ expression was also measured. Compared with the control group, the cerebral cortex, hippocampus, amygdala and hypothalamus in the isoflurane group had significantly more apoptotic cells $(\mathrm{P}<0.05)$. The nuclei of the control group were round and transparent, while shrunken nuclei and condensed chromatin were visible in the isoflurane group. A reduction in synapse number was observed in the isoflurane group compared with the control. By contrast, nuclei shrinkage and the decrease in synaptic number was improved in the $\mathrm{C} 21$ group. PPAR- $\alpha$ and Bcl-2 expression, at the mRNA and protein levels, was significantly reduced in the isoflurane group compared with the control $(\mathrm{P}<0.05)$. $\mathrm{C} 21$ treatment reduced the decrease in PPAR- $\alpha$ and $\mathrm{Bcl}-2$ in the cerebral cortex, hippocampus, amygdala and hypothalamus $(\mathrm{P}<0.05)$. Collectively, it was demonstrated that $\mathrm{C} 21$ prevented apoptosis
\end{abstract}

Correspondence to: Dr Qingfan Zeng, Department of Anesthesiology, The Baiyun Hospital Affiliated to Guizhou Medical University, 108 Gangyu Street, Guiyang, Guizhou 550014, P.R. China

E-mail: zengqingfan18932@126.com

Key words: angiotensin II type 2 receptor, isoflurane, neonatal rats, BCL2, apoptosis regulator, peroxisome proliferator-activated receptor $\alpha$ and synaptic loss induced by general anesthesia in neonatal rats by enhancing the expression of PPAR- $\alpha$ and Bcl-2.

\section{Introduction}

General anesthesia has a great impact on the development of infants and young children (1), and may contribute to the development of learning disabilities $(2,3)$. At the early stage of development, anesthesia and surgery may produce significant cell apoptosis, which reduces hippocampal long-term potentiation $(4,5)$, an important cellular mode of learning and memory (6). A number of anesthetics have been used for the general anesthesia of children. Isoflurane has neuroprotective properties, rapidly induces anesthesia and is metabolized $(7,8)$. Therefore, isoflurane is widely accepted for use in children. However, neurotoxic effects of isoflurane have also been reported. Spatial memory in young and adult animals was impaired following isoflurane anesthesia $(9,10)$. In an animal study, isoflurane administration resulted in the appearance of a large number of apoptotic cells and subsequent cognitive impairment (11). Therefore, it is of clinical significance to identify compounds with the potential to inhibit isoflurane toxicity.

Angiotensin II receptor type 2 (AT2R) is widely expressed in the fetus and in newborns (12). In experimental autoimmune encephalomyelitis models, AT2R is downregulated and an AT2R agonist ameliorates the function of AT2R, which suggests that AT2R is involved in the pathological processes of autoimmune encephalomyelitis (13). Compound (C) 21 is a non-peptide agonist of AT2R, which functions in blood vessel endothelium dilation, inflammatory reaction inhibition and the promotion neuronal repair and regeneration (14-16). However, whether C21 inhibits cell apoptosis caused by isoflurane in neonatal rats has not yet been confirmed.

The BCL2, apoptosis regulator (Bcl-2) is an oncogene which is involved in mitochondria-dependent apoptosis regulation. The expression of Bcl-2 inhibits apoptosis elicited by multiple cytotoxic factors $(17,18)$. In the current study, the protective effects of $\mathrm{C} 21$ on isoflurane-induced apoptosis in neonatal rats were investigated, and the underlying mechanisms were assessed. The data revealed that $\mathrm{C} 21$ inhibited general anesthesia-induced neuronal apoptosis, likely through promoting Bcl-2 expression. 
Table I. Primer sequences used in reverse transcription-quantitative polymerase chain reaction.

\begin{tabular}{lllccc}
\hline Gene & Direction & \multicolumn{1}{c}{$\begin{array}{c}\text { Primer } \\
\text { sequence }\left(5^{\prime}-3^{\prime}\right)\end{array}$} & $\begin{array}{c}\text { Primer } \\
\text { length }(\mathrm{bp})\end{array}$ & $\begin{array}{c}\text { Product } \\
\text { length }(\mathrm{bp})\end{array}$ & $\begin{array}{c}\text { Annealing } \\
\text { temperature }\left({ }^{\circ} \mathrm{C}\right)\end{array}$ \\
\hline Bcl-2 & Forward & GGCATCTTCTCCTTCCAGC & 19 & 265 & 58 \\
\multirow{3}{*}{ GAPDH } & Reverse & AGAGTTCCTCCACCACCGT & 19 & & 58 \\
& Forward & GCAAGTTCAACGGCACAG & 18 & 141 & 58 \\
& Reverse & CGCCAGTAGACTCCACGAC & 19 & & \\
\hline
\end{tabular}

Bcl-2, BCL2 apoptosis regulator.

\section{Materials and methods}

Animals and groups. Specific pathogen-free Sprague Dawley rats ( $\mathrm{n}=8 ; 1: 1$ male:female; weight, $\sim 252 \mathrm{~g}$ ) were purchased from Shanghai Super B\&K Laboratory Animal Co., Ltd. (license number 2013-0016; Shanghai, China) and maintained in a temperature-controlled environment $\left(25^{\circ} \mathrm{C}\right)$ and a humidity of $40-60 \%$ with a standard $12 \mathrm{~h}$ light/dark cycle and ad libitum access to food and water. All experimental procedures were approved by the ethics committee of Guizhou Medical University (Guiyang, China). A total of 18 pups from four litters were randomly divided into three groups ( $\mathrm{n}=6$ in each group; $1: 1$ male:female): i) Control group, ii) isoflurane group and iii) a C21 treatment group. Post-natal day 7 rats inhaled $1.3 \%$ isoflurane (Sigma-Aldrich; Merck KGaA, Darmstadt, Germany) for $3 \mathrm{~h}$ each day for a consecutive 3 days. Following the administration of isoflurane, rats in the $\mathrm{C} 21$ treatment group received $0.1 \mathrm{mlC} 21$ $(1 \mu \mathrm{g} / \mathrm{kg}$; cat. no. C160; Sigma-Aldrich; Merck KGaA) intraperitoneally each day for a consecutive 4 days, while the rats in the isoflurane group received a similar volume of saline. Following treatment, the rats were anesthetized with $1 \%$ sodium pentobarbital $(45 \mathrm{mg} / \mathrm{kg}$; intraperitoneal injection) and decapitated. Rats weighed $10-15 \mathrm{~g}$ at the time of sacrifice. Fresh brain tissues were collected for flow cytometry, enzyme-linked immunosorbent assay (ELISA), reverse transcription-quantitative polymerase chain reaction (RT-qPCR) and western blot analysis, while the brain tissues were fixed for transmission electron microscopy (TEM) and the terminal deoxynucleotidyl-transferase-mediated dUTP nick end-labelling (TUNEL) assay.

Flow cytometry. The cortex, hippocampus, amygdala and hypothalamus were isolated and ground. A single cell suspension was prepared following trypsinization. A metal mesh was applied to isolate the single cells from the homogenates. Cells were centrifuged at $375 \mathrm{xg}$ for $2 \mathrm{~min}$ at $4^{\circ} \mathrm{C}$, and $5 \times 10^{5}$ cells were collected for flow cytometry. Apoptosis was detected using an Annexin V-fluorescein isothiocyanate (FITC)/propidium iodide (PI) Apoptosis kit [cat. no. AP101-100-kit; Hanzhou Multi Sciences (Lianke) Biotech Co., Ltd., Hangzhou, China] according to the manufacturer's protocol. Following staining with Annexin V-FITC (5 $\mu \mathrm{l})$ and PI (10 $\mu \mathrm{l})$ together for $5 \mathrm{~min}$ at room temperature, cells were detected using a flow cytometer (NovoCyte 2060R, ACEA Biosciences, Inc., San Diego, CA, USA) with excitation at $488 \mathrm{~nm}$ and emission at $530 \mathrm{~nm}$. Data were analyzed using FlowJo 10 (FlowJo LLC, Ashland, OR, USA).
Terminal deoxynucleotidyl-transferase-mediated dUTP nick end-labelling (TUNEL) staining. Collected brain tissues were fixed in $10 \%$ formalin at $4^{\circ} \mathrm{C}$ for $24 \mathrm{~h}$ for the TUNEL assay. Cortex, hippocampus, amygdala and hypothalamus were subsequently separated and cryoprotected in $30 \%$ sucrose for $1 \mathrm{~h}$ at $4^{\circ} \mathrm{C}$, prior to slicing into $20 \mu \mathrm{m}$ sections with a freezing microtome. TUNEL staining $(2 \mu \mathrm{l})$ was performed using the ApopTag In Situ Apoptosis Detection kit (cat. no. C1089; Beyotime Institute of Biotechnology, Shanghai, China) at $45^{\circ} \mathrm{C}$ for $2 \mathrm{~h}$, following the manufacturer's protocol. Following this, 3 drops of mounting medium containing 4',6-diamidino-2-phenylindole (cat. no. ab104139; Abcam, Cambridge, UK) was added and the slides were then covered. After staining, the sections were imaged using fluorescence microscopy (Olympus Corporation, Tokyo, Japan). Four fields in each slice were analyzed and apoptotic cells were counted.

TEM. The bilateral hippocampus was fixed in $2.5 \%$ glutaraldehyde at $4^{\circ} \mathrm{C}$ for $2 \mathrm{~h}$, dehydrated in 70, 75, 80, 85 and $95 \%$ ethanol, embedded in paraffin, solidified, and sectioned into $70 \mathrm{~nm}$ slices. Following this, sections were stained with $3 \%$ uranyl acetate and $3 \%$ lead citrate for $7 \mathrm{~min}$ at room temperature and imaged using transmission electron microscopy (80 kV; JEM-1230; JEOL, Ltd., Tokyo, Japan).

ELISA. Peroxisome proliferator-activated receptor (PPAR)- $\alpha$ levels were detected with a PPAR- $\alpha$ ELISA kit (cat. no. m1003331; MLbio, Shanghai, China) according to the manufacturer's protocol. The reagents in the kit were kept at room temperature for $30 \mathrm{~min}$. A standard curve was established. Cortex, hippocampus, hypothalamus and amygdala tissues were homogenized and centrifuged at $11,000 \mathrm{x} \mathrm{g}$ for $10 \mathrm{~min}$ at $4^{\circ} \mathrm{C}$ and the supernatants were used in the ELISA. All standard samples and test samples required three duplicates. A blank control, without sample or enzyme reagent, was used. The absorbance was detected at $450 \mathrm{~nm}$ using a microplate reader (RT-6100; Rayto Life and Analytical Sciences Co., Ltd., Shenzen, China).

$R T-q P C R$. mRNA was extracted from rat cortex, hippocampus, hypothalamus and amygdala using a TRIzol ${ }^{\circledR}$ assay kit (Thermo Fisher Scientific, Inc.). The mRNA was transcribed into cDNA using a PrimeScript ${ }^{\mathrm{TM}}$ RT-PCR Kit (cat. no. DRR014A; Takara Biotechnology Co., Ltd., Dalian, China) according to the manufacturer's protocol $\left(25^{\circ} \mathrm{C}\right.$ for $9 \mathrm{~min}, 37^{\circ} \mathrm{C}$ for $121 \mathrm{~min}$ and $85^{\circ} \mathrm{C}$ for $5 \mathrm{~min}$ ). SYBR Green 

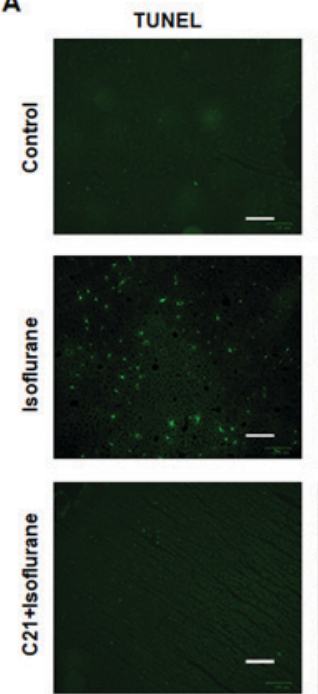

C
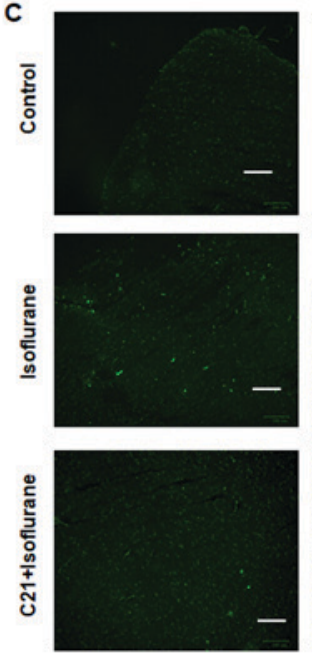

DAPI
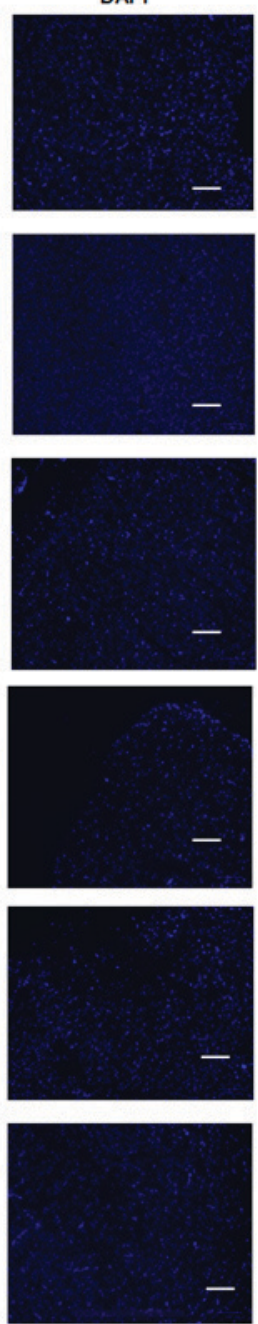

Merge
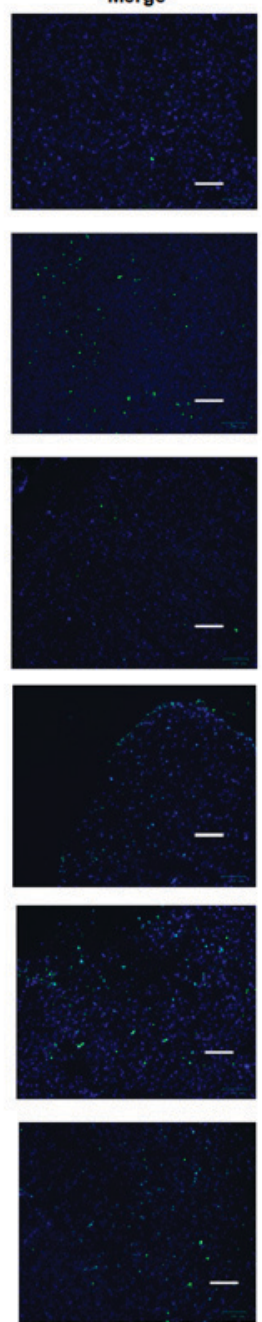
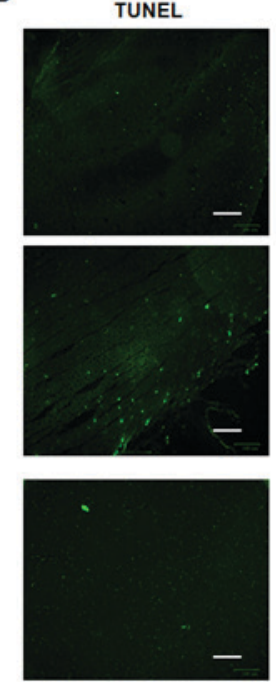

D
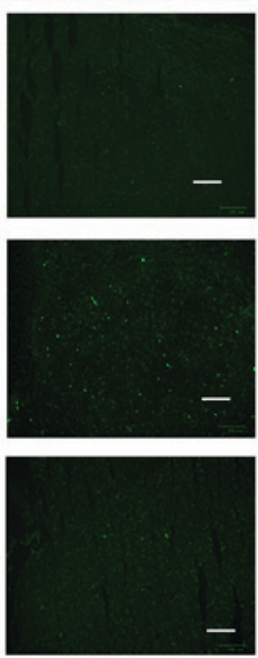
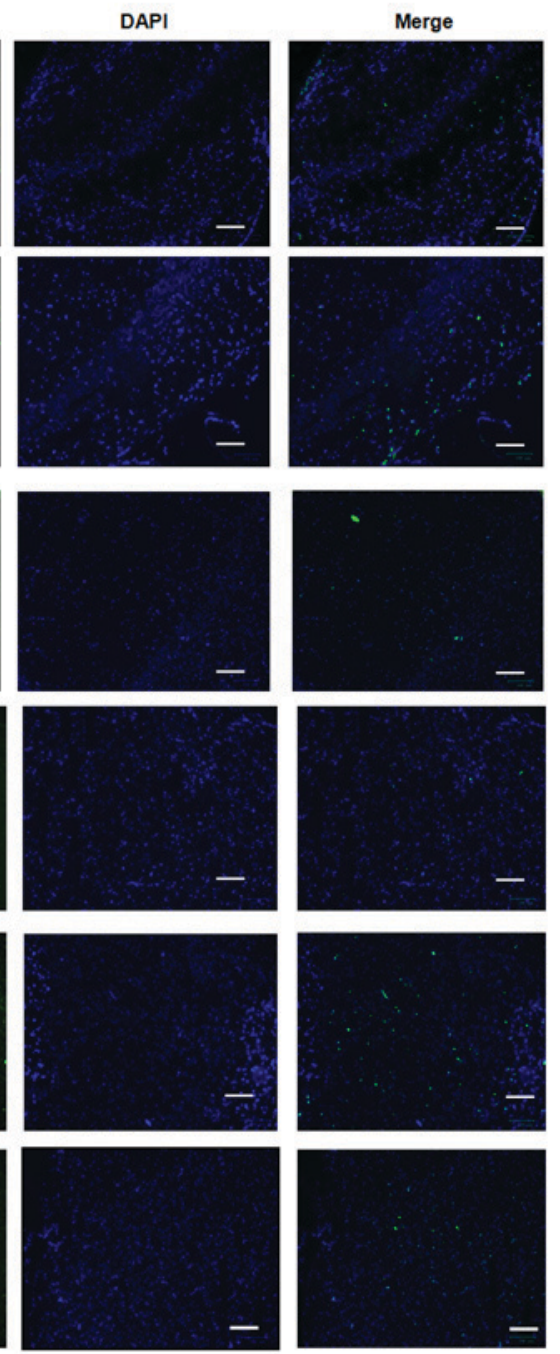

Figure 1. TUNEL assay. C21 reduced isoflurane-induced apoptosis in the (A) cortex, (B) hippocampus, (C) hypothalamus and (D) amygdala. Scale bar, $100 \mu \mathrm{m}$. TUNEL, terminal deoxynucleotidyl-transferase-mediated dUTP nick end labelling; C21, compound 21.

(cat. no. HY-K0501; MedChemExpress, Monmouth Junction, NJ, USA) was used to detect the expression level of Bcl-2 using cDNA as a template. qPCR was performed using the following thermocycling conditions: Initial denaturation at $95^{\circ} \mathrm{C}$ for $10 \mathrm{~min}$; followed by 36 cycles at $95^{\circ} \mathrm{C}$ for $14 \mathrm{sec}$ and $58^{\circ} \mathrm{C}$ for $1 \mathrm{~min}$. The $2^{-\Delta \Delta \mathrm{Cq}}$ method was used to quantify the results as previously described (19), and relative expression was normalized to GAPDH. The primer sequences are listed in Table I.

Western blot analysis. Homogenates from the cortex, hippocampus, amygdala and hypothalamus were obtained from each group and lysed using an illustra triplePrep Kit (cat. no. 28-9425-44; GE Healthcare Life Sciences). The protein levels were detected using a bicinchoninic acid protein assay kit (Beyotime Institute of Biotechnology). Protein samples were separated by $12 \%$ SDS-PAGE and transferred onto nitrocellulose membranes. The membranes were blocked with Tris-buffered saline containing $0.1 \%$ Tween 20 and 5\% fat-free milk for $2 \mathrm{~h}$ at room temperature, and were subsequently incubated overnight at $4^{\circ} \mathrm{C}$ with rabbit antibodies against Bcl-2 (1:1,500; cat. no. bs-0032R; BIOSS, Beijing, China) and GAPDH (cat. no. A007; 1:1,000; ABclonal Biotech

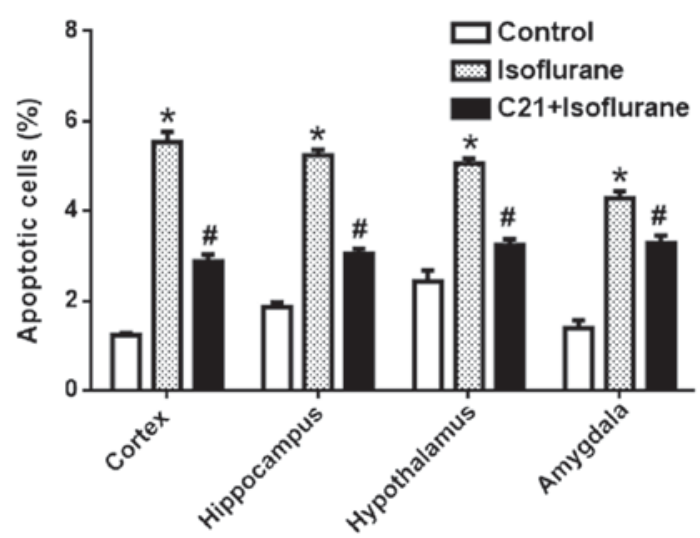

Figure 2. Quantification of the terminal deoxynucleotidyl-transferase-mediated dUTP nick end labelling assay results. The apoptotic rate of each group was calculated. ${ }^{*} \mathrm{P}<0.05$ vs. control group, ${ }^{\#} \mathrm{P}<0.05$ vs. isoflurane group. $\mathrm{C} 21$, compound 21.

Co., Ltd., Woburn, MA, USA). Following this, membranes were incubated with peroxidase-conjugated goat anti-rabbit immunoglobulin G (1:5,000; cat. no. TA140003; OriGene 
A
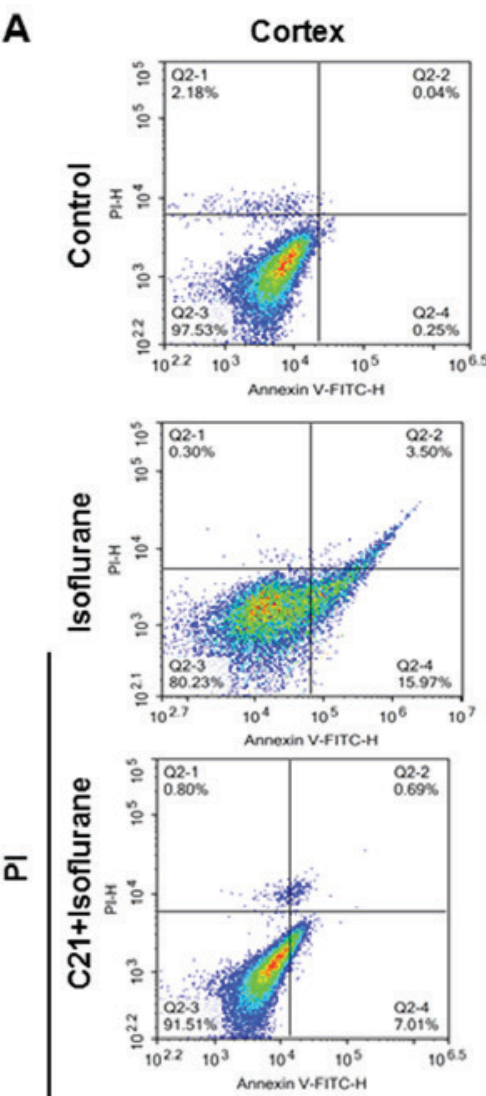

Hippocampus
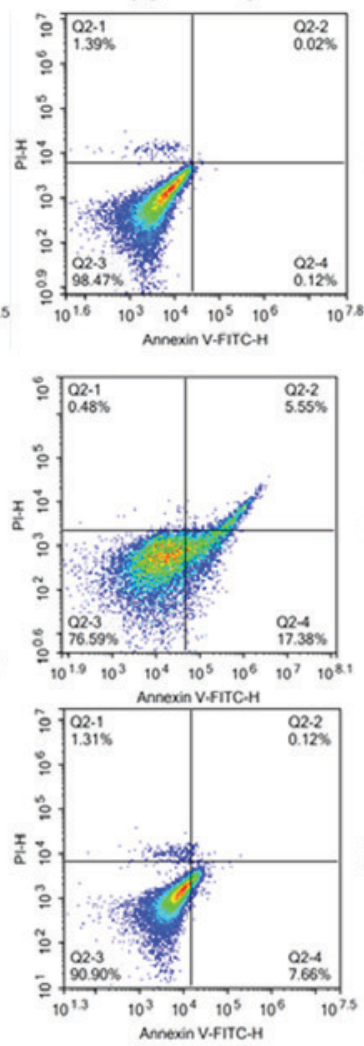

Hypothalamus
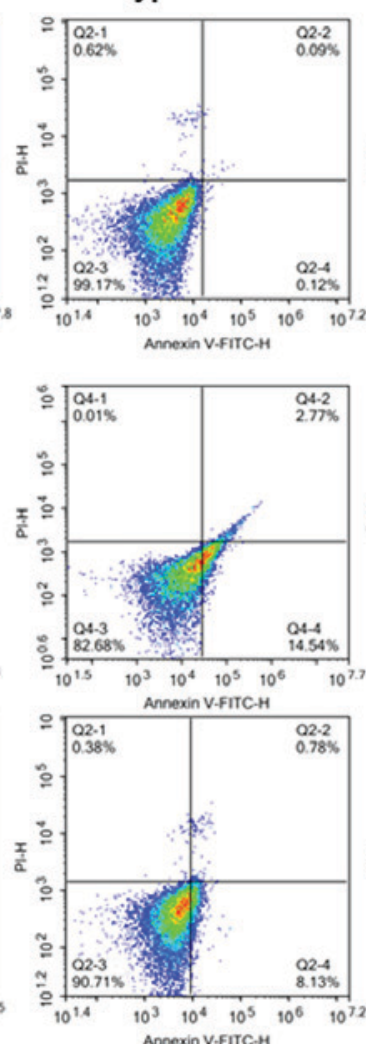
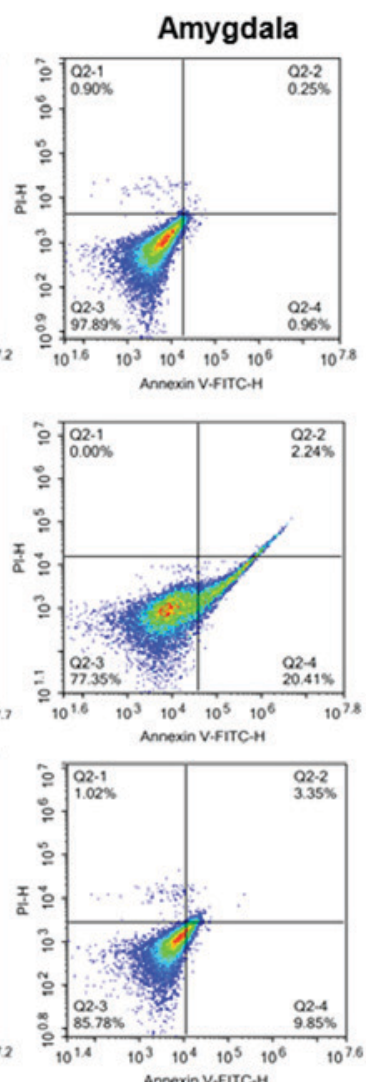

Annexin V-FITC

B

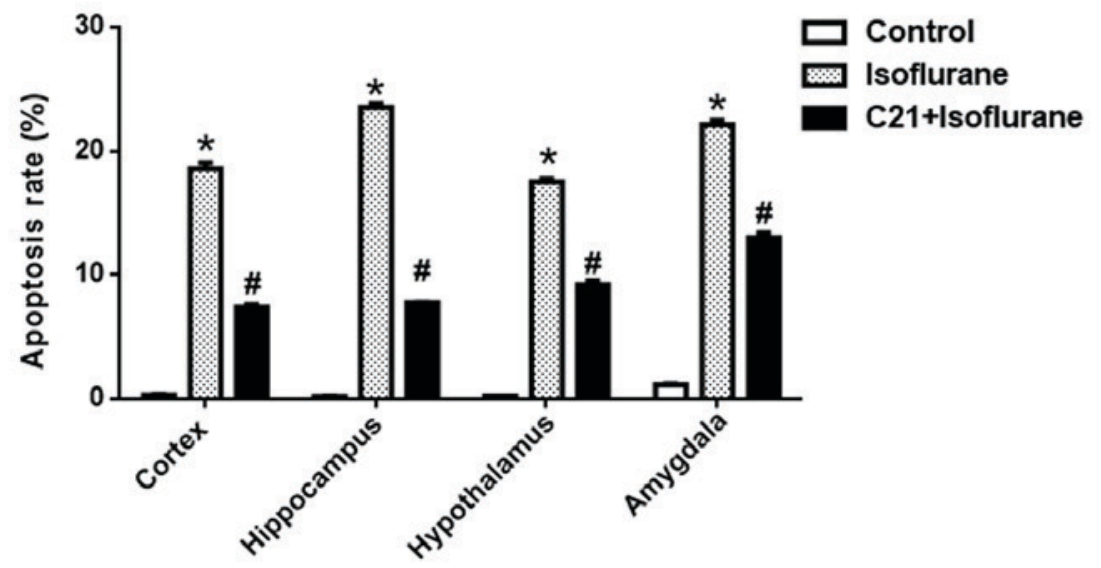

Figure 3. C21 reduces isoflurane-induced cerebral neuronal apoptosis. (A) Representative images of flow cytometric analysis of each brain section. (B) Quantification of the flow cytometry results. ${ }^{*} \mathrm{P}<0.05$ vs. control group, ${ }^{\text {\#}} \mathrm{P}<0.05$ vs. isoflurane group. FITC, fluorescein isothiocyanate; PI, propidium iodide; C21, compound 21.

Technologies, Inc., Beijing, China) for $2 \mathrm{~h}$ at room temperature. A chemiluminescent substrate detection reagent (cat. no. RPN2133; GE Healthcare Life Sciences) was applied to assist with staining. The target band was analyzed using Quantity One version 1.4.6 (Bio-Rad Laboratories, Inc.) for densitometric analysis.

Data analysis. The data are expressed as the mean \pm standard deviation and were statistically analyzed using SPSS 19 (IBM Corp., Armonk, NY, USA). One-way analysis of variance followed by Newman-Keuls post-hoc test was applied to determine statistical significance. All experiments were repeated six times. $\mathrm{P}<0.05$ was considered to indicate a statistically significant difference.

\section{Results}

C21 prevents isoflurane-induced neuronal apoptosis. The TUNEL assay demonstrated that postnatal administration of isoflurane elicited marked apoptosis in the cortex, hippocampus, amygdala and hypothalamus. By contrast, C21 treatment appeared to reduce apoptosis in these four regions 

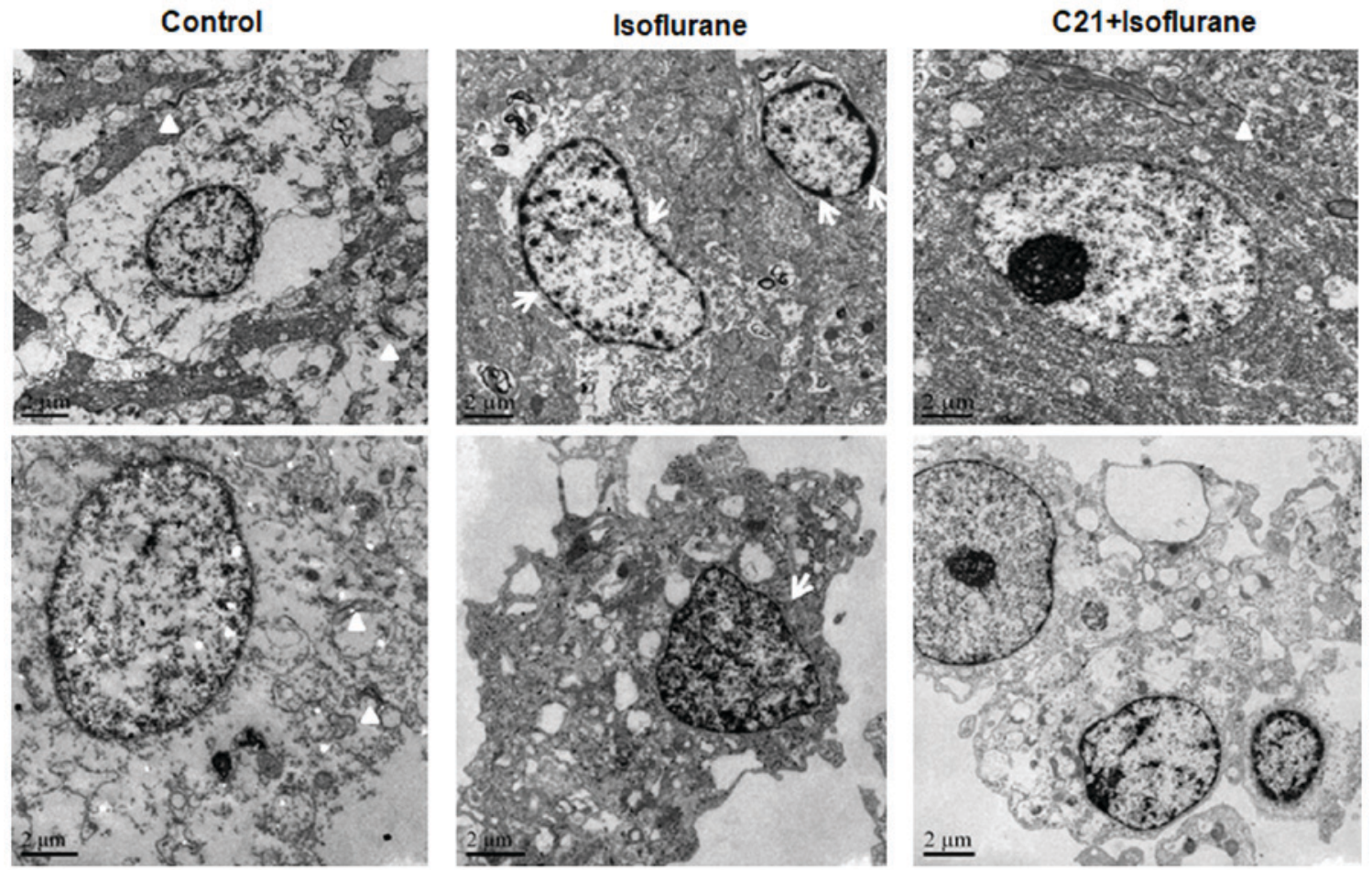

Figure 4. Transmission electron microscopy of the bilateral hippocampus. C21 reduced isoflurane-induced morphological changes. Arrows indicate the condensed chromatin and triangles indicate synapses. C21, compound 21.

(Fig. 1). The apoptotic rates in each group were calculated (Fig. 2). In the control groups, the apoptotic rates were $1.23 \%$ (cortex), $1.86 \%$ (hippocampus), 2.43\% (hypothalamus) and $1.40 \%$ (amygdala). The apoptotic rates in the isoflurane group were $5.53 \%$ (cortex), 5.24\% (hippocampus), 5.05\% (hypothalamus) and $4.28 \%$ (amygdala). The apoptotic rates in the C21+Isoflurane group were $2.87 \%$ (cortex), 3.05\% (hippocampus), 3.15\% (hypothalamus) and 3.29\% (amygdala).

Apoptosis was further confirmed by flow cytometry. As shown in Fig. 3, approximately $20 \%$ of cells were apoptotic in the isoflurane group, which was significantly reduced by $\mathrm{C} 21$ treatment $(\sim 8 \%)$.

TEM further confirmed that isoflurane induced apoptosis in the hippocampus, which was ameliorated by $\mathrm{C} 21$ treatment (Fig. 4). The nuclei of the cells in the control group were round and transparent. The nuclei of the cells in the isoflurane group were shrunken, and condensed chromatin was evident. A marked reduction in synapse numbers was observed in the isoflurane group, but not in the control group. By contrast, the nuclear shrinkage and decrease in synapse number was less prominent in the $\mathrm{C} 21$ group.

C21 increases PPAR- $\alpha$ expression. PPAR- $\alpha$ levels in several brain regions were measured using ELISA. As shown in Fig. 5, isoflurane exposure significantly reduced PPAR- $\alpha$ levels in the four selected regions, compared with the control. By contrast, C21 treatment significantly elevated PPAR- $\alpha$ levels compared with the isoflurane group.

C21 increases Bcl-2 expression. Bcl-2 expression in different regions was detected at both the mRNA and protein level. Fig. 6 shows that, isoflurane exposure significantly reduced

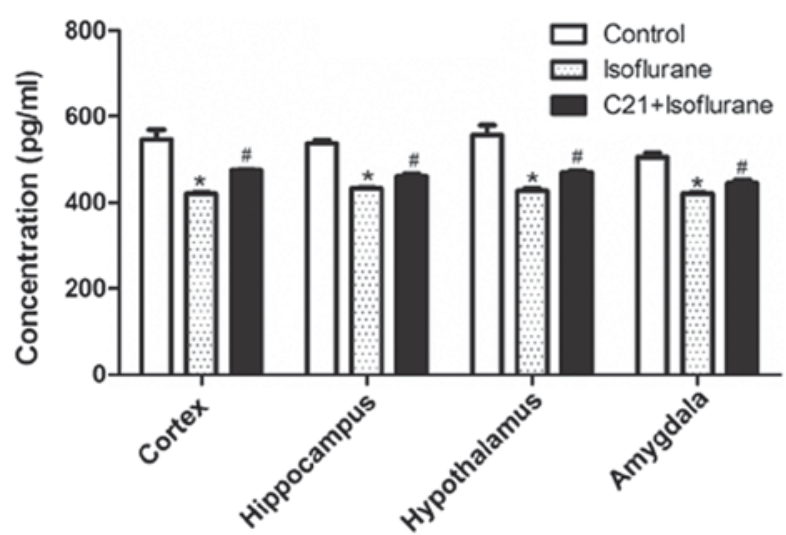

Figure 5. Enzyme-linked immunosorbent assay of PPAR- $\alpha$ expression. C21 increased PPAR- $\alpha$ levels following isoflurane administration. ${ }^{*} \mathrm{P}<0.05$ vs. control group, ${ }^{\#} \mathrm{P}<0.05$ vs. isoflurane group. PPAR- $\alpha$, peroxisome proliferator-activated receptor a. C21, compound 21 .

Bcl-2 mRNA levels in the four selected regions. Additionally, C21 treatment significantly elevated Bcl-2 mRNA expression. Western blot analysis also demonstrated that isoflurane exposure significantly reduced $\mathrm{Bcl}-2$ protein expression in the four selected regions. Furthermore, $\mathrm{C} 21$ treatment significantly increased $\mathrm{Bcl}-2$ protein expression.

\section{Discussion}

General anesthetics, not only affect the development of neurons, but also damage them $(4,5)$. Previous findings have demonstrated that general anesthetics cause extensive cell death in the brain, reduce the number of brain cells and 

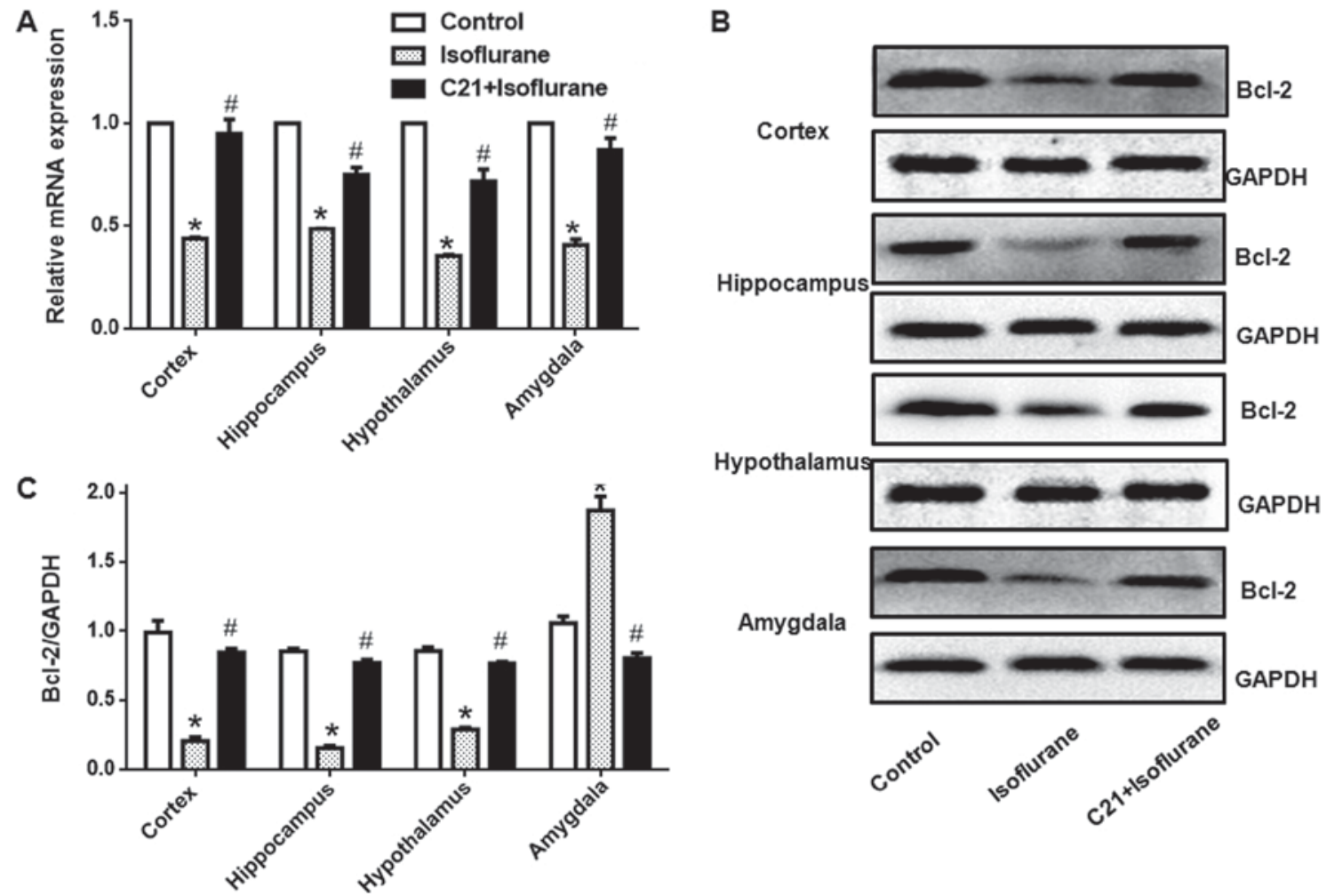

Figure 6. Reverse transcription-quantitative polymerase chain reaction and western blotting was performed to determine Bcl-2 gene and protein expression. (A) $\mathrm{C} 21$ increased Bcl-2 mRNA and (B) protein expression following isoflurane administration. (C) Western blotting results were quantified by densitometric analysis. ${ }^{*} \mathrm{P}<0.05$ vs. control group, ${ }^{,} \mathrm{P}<0.05$ vs. isoflurane group. Bcl-2, BCL2, apoptosis regulator.

decrease synaptic function, resulting in cognitive impairment, and this damage extends to adulthood $(20,21)$. Neonatal rats are the most commonly used model to investigate neurodevelopment (22). The present study investigated the therapeutic effect of C21 on isoflurane-induced apoptosis in neonatal rats. The results revealed that isoflurane exposure caused marked apoptosis in the cortex, hippocampus, amygdala and hypothalamus.

C21 is an AT2R agonist, which has vasodilatory activity, and may protect neuronal function (23). C21-mediated neuroprotection has been widely reported in ischemic injury, vascular dementia and diabetes (24-26). In addition, this neuroprotective effect is likely mediated through an AT2R-dependent pathway or an AT2R-independent pathway (15). In the current study, AT2R expression was not directly measured, in part due to the limitations of available techniques to localize this receptor. However, the neuroprotective activity of C21 in general anesthesia-induced cerebral injury was observed. Synapse number is closely associated with synaptic function, as well as learning and memory (27). TEM analysis revealed that the number of synapses was reduced by isoflurane treatment. C21 treatment increased the number of synapses, which suggested that C21 improved impaired axon and synapse development, which was induced by isoflurane exposure. Neuronal apoptosis is an important component of neurotoxicity $(28,29)$. In immature animal neurons, general anesthesia produces severe cytotoxicity, particularly in synaptic growth $(20,21)$. In the present study, two different methods were utilized to detect apoptosis. A similar trend in each group was observed in the two methods, with C21 treatment attenuating the apoptosis induced by isoflurane. However, the apoptotic rates detected via the two methods were inconsistent, which may have been caused by the different analysis methods utilized in the present study. Flow cytometry may be more effective in determining total apoptosis.

Mitochondrial structure and $\mathrm{Bcl}-2$ family protein expression at the outer membrane destroys mitochondrial permeability transition and mitochondrial pore function. Isoflurane activates the mitochondria-dependent apoptosis pathway and downregulates anti-apoptotic protein B cell lymphoma-extra large expression in the immature brain $(30,31)$. In the current study, TUNEL and flow cytometry were used to detect apoptosis in the cerebral cortex, hippocampus, amygdala and hypothalamus, and apoptosis in the isoflurane group was significantly increased. These results suggested that apoptosis may have been a major cause of the impairment of neurodevelopment following isoflurane exposure. Notably, apoptosis was ameliorated by $\mathrm{C} 21$ treatment. These results suggested that C21 had a protective effect against neuronal apoptosis induced by isoflurane. Previous studies have also demonstrated that isoflurane exposure reduces Bcl-2 expression and elicits apoptosis in cerebral tissue (32). Consistent with these findings, the results of the current study also confirmed that the expression of Bcl-2 in the isoflurane groups was significantly decreased. In addition, the present results suggested that $\mathrm{C} 21$ protected neonatal rat brain tissue by increasing the expression of Bcl-2.

PPAR- $\alpha$ is a recently discovered target for vascular pathological alterations (33). It is a ligand-activated transcription factor that belongs to the nuclear hormone receptor superfamily. When PPAR binds with its ligand, it promotes 
the gene transcription of target cells, and regulates cell cycle, differentiation and apoptosis in various cell types, thereby regulating blood glucose, lipid metabolism and cell differentiation (34). Certain studies have demonstrated that PPAR- $\alpha$ has anti-inflammatory and anti-apoptotic effects $(35,36)$. The results of the current study demonstrated that isoflurane decreased PPAR- $\alpha$ levels in the cerebral cortex, hippocampus, amygdala and hypothalamus. This revealed that isoflurane may have impaired neurodevelopment through PPAR- $\alpha$ expression regulation. Notably, C21 treatment elevated PPAR- $\alpha$ levels in the cerebral cortex, hippocampus, amygdala and hypothalamus. However, the mechanism through which C21 activated PPAR- $\alpha$ still requires further clarification. Based on these data, C21 may be effective in clinically preventing the adverse effects induced by isoflurane anesthesia. However, further studies using animal models as well as clinical studies are required prior to the administration of $\mathrm{C} 21$ to children.

In summary, isoflurane damaged the neonatal rat brain by altering the expression of $\mathrm{Bcl}-2$ in the brain, and this was ameliorated by $\mathrm{C} 21$ administration. The present study provided a theoretical basis for the safer clinical use of anesthetics.

\section{Acknowledgements}

Not applicable.

\section{Funding}

The present study was supported by the Science and Technology fund of Guizhou Province (grant no. LH-2015-7394).

\section{Availability of data and materials}

The datasets used during the present study are available from the corresponding author upon reasonable request.

\section{Authors' contributions}

JY, LY, JW and HX performed the experiments and analyzed the data. QZ designed the study and wrote the manuscript.

\section{Ethics approval and consent to participate}

All experimental procedures were approved by the ethics committee of Guizhou Medical University.

\section{Patient consent for publication}

Not applicable.

\section{Competing interests}

The authors declare that they have no competing interests.

\section{References}

1. Deng M, Hofacer RD, Jiang C, Joseph B, Hughes EA, Jia B Danzer SC and Loepke AW: Brain regional vulnerability to anaesthesia-induced neuroapoptosis shifts with age at exposure and extends into adulthood for some regions. Br J Anaesth 113: 443-451, 2014
2. Zhang J, Dong Y, Zhou C, Zhang Y and Xie Z: Anesthetic sevoflurane reduces levels of hippocalcin and postsynaptic density protein 95. Mol Neurobiol 51: 853-863, 2015.

3. Zhao T, Li Y, Wei W, Savage S, Zhou L and Ma D: Ketamine administered to pregnant rats in the second trimester causes long-lasting behavioral disorders in offspring. Neurobiol Dis 68: 145-155, 2014.

4. Cheng Y,HeL,Prasad V,Wang S and Levy RJ: Anesthesia-induced neuronal apoptosis in the developing retina: A window of opportunity. Anesth Analg 121: 1325-1335, 2015.

5. Noguchi KK, Johnson SA, Dissen GA, Martin LD, Manzella FM, Schenning KJ, Olney JW and Brambrink AM: Isoflurane exposure for three hour triggers apoptotic cell death in neonatal macaque brain. Br J Anaesth 119: 524-531, 2017.

6. Zhu G, Liu Y, Wang Y, Bi X and Baudry M: Different patterns of electrical activity lead to long-term potentiation by activating different intracellular pathways. J Neurosci 35 : 621-633, 2015.

7. Zhao DA, Bi LY, Huang Q, Zhang FM and Han ZM: Isoflurane provides neuroprotection in neonatal hypoxic ischemic brain injury by suppressing apoptosis. Braz J Anesthesiol 66: 613-621, 2016.

8. Sosunov SA, Ameer X, Niatsetskaya ZV, Utkina-Sosunova I, Ratner VI and Ten VS: Isoflurane anesthesia initiated at the onset of reperfusion attenuates oxidative and hypoxic-ischemic brain injury. PLoS One 10: e0120456, 2015.

9. Kalkman CJ, Peelen L, Moons KG, Veenhuizen M, Bruens M, Sinnema G and de Jong TP: Behavior and development in children and age at the time of first anesthetic exposure. Anesthesiology 110: 805-812, 2009.

10. Flick RP, Wilder RT, Sprung J, Katusic SK, Voigt R, Colligan R, Schroeder DR, Weaver AL and Warner DO: Anesthesia and cognitive performance in children: No evidence for a causal relationship. Are the conclusions justified by the data? Response to Bartels et al, 2009. Twin Res Hum Genet 12: 611-614, 2009.

11. Li X, Wei K, Hu R, Zhang B, Li L, Wan L, Zhang C and Yao W: Upregulation of Cdh1 attenuates isoflurane-induced neuronal apoptosis and long-term cognitive impairments in developing rats. Front Cell Neurosci 11: 368, 2017.

12. Villela D, Leonhardt J, Patel N, Joseph J, Kirsch S, Hallberg A, Unger T, Bader M, Santos RA, Sumners C and Steckelings UM: Angiotensin type 2 receptor (AT2R) and receptor Mas: A complex liaison. Clin Sci 128: 227-234, 2015.

13. Valero-Esquitino V, Lucht K, Namsolleck P, Monnet-Tschudi F, Stubbe T, Lucht F, Liu M, Ebner F, Brandt C, Danyel LA, et al: Direct angiotensin type 2 receptor (AT2R) stimulation attenuates T-cell and microglia activation and prevents demyelination in experimental autoimmune encephalomyelitis in mice. Clin Sci (Lond) 128: 95-109, 2015.

14. Wang Y, Del Borgo M, Lee HW, Baraldi D, Hirmiz B, Gaspari TA, Denton KM, Aguilar MI, Samuel CS and Widdop RE: Anti-fibrotic potential of $\mathrm{AT}_{2}$ receptor agonists. Front Pharmacol 8: 564, 2017.

15. Bennion DM, Isenberg JD, Harmel AT, DeMars K, Dang AN, Jones CH, Pignataro ME, Graham JT, Steckelings UM, Alexander JC, et al: Post-stroke angiotensin II type 2 receptor activation provides long-term neuroprotection in aged rats. PLoS One 12: e0180738, 2017.

16. Pandey A and Gaikwad AB: Compound 21 and Telmisartan combination mitigates type 2 diabetic nephropathy through amelioration of caspase mediated apoptosis. Biochem Biophys Res Commun 487: 827-833, 2017.

17. Um HD: Bcl-2 family proteins as regulators of cancer cell invasion and metastasis: A review focusing on mitochondrial respiration and reactive oxygen species. Oncotarget 7: 5193-5203, 2016.

18. Zheng JH, Viacava Follis A, Kriwacki RW and Moldoveanu T: Discoveries and controversies in BCL-2 protein-mediated apoptosis. FEBS J 283: 2690-2700, 2016.

19. Livak KJ and Schmittgen TD: Analysis of relative gene expression data using real-time quantitative PCR and the 2(-Delta Delta C (T)) method. Methods 25: 402-408, 2001.

20. Wang YL, Chen X and Wang ZP: Detrimental effects of postnatal exposure to propofol on memory and hippocampal LTP in mice. Brain Res 1622: 321-327, 2015.

21. Wang YL, Li F and Chen X: Pten inhibitor-bpV ameliorates early postnatal propofol exposure-induced memory deficit and impairment of hippocampal LTP. Neurochem Res 40: 1593-1599, 2015. 
22. Li J, Yang S and Zhu G: Postnatal calpain inhibition elicits cerebellar cell death and motor dysfunction. Oncotarget 8: 87997-88007, 2017.

23. Koulis C, Chow BS, McKelvey M, Steckelings UM, Unger T, Thallas-Bonke V, Thomas MC, Cooper ME, Jandeleit-Dahm KA and Allen TJ AT2R agonist, compound 21, is reno-protective against type 1 diabetic nephropathy. Hypertension 65: 1073-1081, 2015.

24. Iwanami J, Mogi M, Tsukuda K, Steckelings UM, Unger T, Thallas-Bonke V, Thomas MC, Cooper ME, Jandeleit-Dahm KA, Allen TJ, et al: Possible synergistic effect of direct angiotensin II type 2 receptor stimulation by compound 21 with memantine on prevention of cognitive decline in type 2 diabetic mice. Eur J Pharmacol 724: 9-15, 2014

25. Min LJ, Mogi M, Tsukuda K, Jing F, Ohshima K, Nakaoka H, Kan-No H, Wang XL, Chisaka T, Bai HY, et al: Direct stimulation of angiotensin II type 2 receptor initiated after stroke ameliorates ischemic brain damage. Am J Hypertens 27: 1036-1044, 2014.

26. Iwanami J, Mogi M, Tsukuda K, Wang XL, Nakaoka H, Kan-no H, Chisaka T, Bai HY, Shan BS, Kukida M and Horiuchi M: Direct angiotensin II type 2 receptor stimulation by compound 21 prevents vascular dementia. J Am Soc Hypertens 9: 250-256, 2015.

27. Zhu G, Wang Y, Li J and Wang J: Chronic treatment with ginsenoside Rg1 promotes memory and hippocampal long-term potentiation in middle-aged mice. Neuroscience 292: 81-89, 2015.

28. Finkel T and Holbrook NJ: Oxidants, oxidative stress and the biology of ageing. Nature 408: 239-247, 2000.

29. Zhu G, Wang X, Wu S, Li X and Li Q: Neuroprotective effects of puerarin on 1-methyl-4-phenyl-1,2,3,6-tetrahydropyridine induced Parkinson's disease model in mice. Phytother Res 28 : 179-186, 2014
30. Ozaki M, Deshpande SS, Angkeow P, Bellan J, Lowenstein CJ, Dinauer MC, Goldschmidt-Clermont PJ and Irani K: Inhibition of the Rac1 GTPase protects against nonlethal ischemia/reperfusion-induced necrosis and apoptosis in vivo. FASEB J 14 418-429, 2000

31. Lennon SV, Martin SJ and Cotter TG: Dose-dependent induction of apoptosis in human tumour cell lines by widely diverging stimuli. Cell Prolif 24: 203-214, 1991.

32. Li W, Li DY, Zhao SM, Zheng ZJ, Hu J, Li ZZ and Xiong SB: Rutin attenuates isoflurane-induced neuroapoptosis via modulating JNK and p38 MAPK pathways in the hippocampi of neonatal rats. Exp Ther Med 13: 2056-2064, 2017.

33. Monsalve FA, Pyarasani RD, Delgado-Lopez F and Moore-Carrasco R: Peroxisome proliferator-activated receptor targets for the treatment of metabolic diseases. Mediators Inflamm 2013: 549627, 2013

34. Qian G, Fan W, Ahlemeyer B, Karnati S and Baumgart-Vogt E: Peroxisomes in different skeletal cell types during intramembranous and endochondral ossification and their regulation during osteoblast differentiation by distinct peroxisome proliferator-activated receptors. PLoS One 10: e0143439, 2015.

35. Fong WH, Tsai HD, Chen YC, Wu JS and Lin TN: Anti-apoptotic actions of PPAR-gamma against ischemic stroke. Mol Neurobiol 41: 180-186, 2010.

36. Crisafulli C, Bruscoli S, Esposito E, Mazzon E, Di Paola R, Genovese T, Bramanti P, Migliorati G and Cuzzocrea S: PPAR- $\alpha$ contributes to the anti-inflammatory activity of $17 \beta$-estradiol. J Pharmacol Exp Ther 331: 796-807, 2009. 